Industrial Dust, 2nd ed. By Philip Drinker and Theodore Hatch. (Pp. $\mathrm{x}+401$; 148 figures. 71s. 6d. ; $\$ 10.00$.) New York, London and Toronto : McGrawHill Book Co. Inc. 1954.

This second edition of a book which on its first appearance was greeted as a standard work is a welcome event. In the past 20 years or so a great amount of work has been done on all aspects of the dust problem in industry. Readers of this journal are well aware of the many extensive medical studies that have been carried out. Side by side with these there have been important investigations of the nature of various dusts, of methods of sampling and examining dusts, including microscopic methods, and of the mechanics of dust particles. New methods for the control of dusts have been devised and old ones improved, and the principles of air filtration have been investigated and applied to respiratory protective devices.

The results of recent work are incorporated in this new edition which contains nearly 90 more pages than its predecessor. In general arrangement the new edition is much the same as the old one, but some parts are much expanded and here and there some paragraphs have been dropped.

The initial chapter on the physical properties of dusts, fumes, and mists contains much new material. The earlier discussion of the effects of dusts and fumes upon man is much extended, and there is in addition a new chapter on dust retention by man. A new chapter on the appraisal of dustiness deals with such considerations as frequency of sampling, weighting of dust exposures, the volume of a sample, and the accuracy required. Sampling instruments are discussed in the light of recent investigations and there is a valuable comparison of such instruments. In the examination of airborne dusts the determination of particle size is of great importance, and this topic is discussed at some length. The remaining chapters on control of the dust hazard, local exhaust systems, air-cleaning apparatus, filtration, and dust respirators and air masks have all been overhauled and largely re-written.

A vast amount of work has gone into the preparation of this new edition with the result that the book is thoroughly up to date. As is well said in the authors' preface, control of the dust hazard in industry is the joint duty of the physician and the engineer. The book is written from the engineer's standpoint, but it will be invaluable also to the industrial doctor who so often has to appraise the value of a dust control system. The book is well worthy of its distinguished authors. It is well produced and well indexed.

\section{THOMAS BEDFORD}

Modern Occupational Medicine. Edited by A. J. Fleming, C. A. D'Alonzo, and J. A. Zapp. (Pp. 414 ; 44 illustrations, 1 in colour. 75s.) London: Henry Kimpton. 1954.

This book is a collection of papers written by 20 members of the staff of the American firm E. I. du Pont de Nemours and Company. It is an account of the service provided in an important but limited field of industrial medicine by a group of men whose opinions are naturally influenced by the special nature of their work and environment. This explains the choice of some subjects and the important omissions from a book whose title leads one to expect a more informative and comprehensive study than is actually given. Many of the papers are in fact little more than a competent précis of information that can now be found in several modern textbooks, but the editors explain their concise form by the fact that the book is intended to be "useful to physicians, executives, safety engineers, and chemists in industry".

In his introductory chapter the Medical Director describes the functions of an occupational medical service, which to be adequate must include an exhaustive annual medical examination for every worker and provide a full-time physician for every thousand individuals employed. The need for medical staff on this scale becomes apparent when it is appreciated, for instance, that there are well over 200 items in the form of signs and symptoms or diseases to be recorded for every prospective employee. It is advocated that every initial examination should include a chest radiograph, a blood count, an audiogram, and a Wassermann test or its equivalent ; in addition routine electrocardiograms are recommended on all applicants of 40 years of age or over. The Company employs 130 full-time and 36 parttime physicians.

The latter half of the chapter entitled " History of Industrial Medicine" is devoted to the admittedly notable contributions made by the United States during the twentieth century including an enthusiastic tribute to Dr. Gehrmann, the du Pont Medical Director. English pioneers in the field are sadly neglected in this paper and the work of Sir Thomas Legge, for example, is dismissed in a few words.

In a comparatively long paper Dr. Foulger discusses the factors that produce what he terms "stress", or slight deviations from the " normal " in otherwise healthy workers, and simple practical means of estimating this state. The principle that Dr. Foulger has so long advocated is commendable but his methods of estimation are still controversial and generally unacceptable.

There follow three chapters that describe the investigation of the toxicity of new chemicals, the protective devices available for workmen, and the important contribution made by an industrial hygiene laboratory in maintaining a healthy factory environment. These are admirably concise accounts of valuable assets to a medical service in a chemical industry.

The chapters on " Physical Environment ", " Fatigue ", "Inplant Feeding" (canteens), and "Chemical Health Hazards " contain items of interest but are too brief to provide much more than a summary of established knowledge. Dr. Fleming, for example, gives an authoritative account of chemical hazards but has only half a page to spare for lead, mercury, or phenol compounds, while a whole chapter is devoted by one of his colleagues to chemicals affecting the carotid sinus. "Industrial Noise" and "Radioactive Hazards" are subjects that must now be included in any book of this kind and 
here they appropriately follow the paper on physical environment. There is surprisingly no reference to lighting and colour in factories.

One might have expected the special prominence given to medico-legal aspects to which an entire chapter is devoted and there are repeated references throughout the book to the growing practice of litigation. Initial medical examinations, medical records, and even treatment may have legal implications at a later date, and every accident involves a probable claim for compensation. One cannot help sympathizing with the contributor who describes at length the necessary qualities of a good medical witness and with our professional colleagues in America who are apparently so often involved in these disputes.

Two unusual papers on the problem of anxiety states among employees offer methods of treatment that will seem strangely unorthodox to the English mind. They recommend in general what is described as effective discipline which condemns " a policy of humoring and appeasement ... or rearranging the external environment to suit his (the patient's) fancied needs ". This seems to imply a firm hand by supervisor and doctor working conjointly, a policy which will apparently produce better results than other forms of therapy and in particular "preoccupation with long histories and diagnostic minutiae".

The book has some surprising omissions and there is little or no information, for example, on the pneumoconioses, the occupational traumatic, infective and malignant diseases, or the health of young persons and the elderly. Several papers will seem almost rudimentary to industrial medical officers but the majority compensate for their lack of detail with bibliographies which in a few instances are quite impressive. The book is nevertheless a notable achievement by the staff of one firm although it is obviously intended more especially for the benefit of safety engineers and chemists. The general picture of the work of a medical service in a large industrial enterprise of international repute is well depicted and should be studied by everyone concerned with occupational health. The opinions of our American colleagues are stimulating and provide food for thought, however unpalatable in some respects to us in Great Britain.

D. KENWIN HARRIS

The Casualty Department. By T. G. Lowden. (Pp. viii +278 ; illustrated. 37s. 6d.) London and Edinburgh : E. \& S. Livingstone. 1955.

Although Mr. Lowden has written his book primarily for the guidance of young men and women taking up casualty work, it can also be read with profit by those responsible for the treatment of the injured in industry. The clinical features of the common conditions likely to be met with in a casualty department are well described and the treatment advised is generally in accordance with accepted modern thought, but it is surely questionable whether many people suffering from acute tenosynovitis are still subjected to absolute fixation of the limb and a prohibition on work for three weeks. Nevertheless, the author's recommendations are in most respects very sound and it is greatly to be hoped that heed will be taken of what he has to say about the proper use of penicillin and other antibiotics.

Mr. Lowden obviously knows his working men, for after describing the classical treatment for sprained finger and mallet finger he admits that they do not usually find it acceptable.

He lays stress on simplicity as the keynote to restoration of function and quite rightly considers that " repeated function of the injured member in ways it is used to does more to restore ability than twice as much organized exercise". But, he does not overlook the importance of good treatment from the outset and is strongly of the opinion that the best way of avoiding compensation neurosis is "to get the patients well of their organic conditions swiftly and effectively: to maintain an atmosphere of optimism and efficiency : to establish a reputation for rapid recovery and good results - to be good at the job. If everyone gets better in a few days no one has time to become neurotic". In fact the perfect picture of the well run works surgery !

A deep understanding of the many problems which arise in dealing with industrial injuries and of the importance of a right approach to the patient runs right through this book and sets a pattern which would save many thousands of man/hours every year if it were followed by all accident surgeons. Attention is drawn to the importance of maintaining close touch with industrial health departments, and the help that may be obtained by drawing on the experience of their medical officers is emphasized. Special praise is given to the arrangements made by the Association of British Chemical Manufacturers and used by its member firms.

The organization of a casualty department is described fully and the legal aspects are also dealt with in considerable detail.

This book is well produced, well illustrated, and most readable : it should be in the hands of all industrial medical officers.

G. F. Keatinge

The Halogenated Hydrocarbons ; Toxicity and Potential Dangers. P.H.S. Pub. No. 414. By W. F. von Oettingen. (Pp. ix +430 ; $\$ 2.50$ cents.) Washington : U.S. Govt. Printing Office. 1955.

In the field of toxicology Dr. von Oettingen is probably at least as well known for his literary compilations as for his experimental contributions. The present volume is cast in a characteristic mould calculated to arouse the admiration of the reader for the assiduity rather than for the imagination of the author. In just over 400 pages some account is given of about 320 compounds. For a majority little more than bare data on their physical and chemical properties is given. Nevertheless, the fact that no reference is made to work describing the biological properties of a compound may be taken as good evidence that no such publication yet exists. This seems to be a reasonable deduction from a study of the accounts of well known compounds. Here the author has combed the literature both of America and Europe with great care and also included references to works that must have a very limited circulation. 